Sharif University of Technology
Scientia Iranica
SCIENTIA
I RAN I C A
http://scientiairanica.sharif.edu

\title{
Design of an efficient vehicle-actuated signal control logic for signalized intersections
}

\author{
Z. Cakici ${ }^{a, 1, *}$, Y. Sazi Murat ${ }^{\text {b }}$, and M. Mutlu Aydin ${ }^{c}$ \\ a. Bayburt University, Faculty of Engineering, Department of Civil Engineering, Bayburt 69000, Turkey. \\ b. Pamukkale University, Faculty of Engineering, Department of Civil Engineering, Denizli 20160, Turkey. \\ c. Ondokuz Mayıs University, Faculty of Engineering, Department of Civil Engineering, Samsun 55000, Tukey.
}

Received 24 November 2020; received in revised form 14 April 2021; accepted 19 July 2021

\author{
KEYWORDS \\ Fluctuated traffic \\ demand; \\ Vehicle-actuated \\ management; \\ Delay; \\ Fixed-time \\ management; \\ Simulation.
}

\begin{abstract}
The effectiveness of fixed-time management systems dramatically decreases in case of fluctuating traffic demands in signalized intersection approaches. The result is the utter waste of time in traffic to be followed by material, psychological, and ecological problems. In recent years, to minimize the negative impacts of these problems, many researchers have focused on Intelligent Transportation Systems (ITS). As it is known, one of the applications of ITS is called vehicle-actuated (traffic-actuated) management systems. Because the success of these types of applications is directly related to the created control logic, the selection of the most proper control parameters for the created control logic is an important issue. This study aims to create an effective control logic and flow chart for the vehicle-actuated management system. At the end of the analyses, it is seen that the created vehicle-actuated management system can adapt to fluctuations in traffic demands in signalized intersection approaches. Average vehicle delays, fuel consumptions, and exhaust emissions can be reduced significantly by the created system. In case of fluctuations in traffic demands in intersection approaches, it is concluded that the performance of the intersection may increase enormously because of the created vehicle-actuated management system.

(C) 2022 Sharif University of Technology. All rights reserved.
\end{abstract}

\section{Introduction}

Economic and technological developments all over the world make life easier. However, this situation may cause several negative effects in many areas. Highways are undoubtedly one of the areas where a number of problems may arise. In parallel with the increase in demand for passenger and freight transportation, the number of vehicles has increased. This increase can

1. Present address: Faculty of Engineering, Department of Civil Engineering, İzmir Democracy University, İzmir 35140, Turkey.

*. Corresponding author. Tel.: +90 5542045924 E-mail address: civilengineerziyacakici@gmail.com (Z. Cakici)

doi: $10.24200 /$ sci. 2021.57231 .5126 cause many economic and environmental problems [13]. To minimize or eliminate the negative effects of these problems on humans and the environment, geometric-topographic and operational arrangements in road networks can be pointed out as important parts of environment-economy-friendly measures and reasonable solutions. At this stage, scientific-based analysis and solution approaches should be preferred. Minimizing the stop numbers and delays is an important step to solve this problem at signalized intersections [4]. The minimization of delays and stops at signalized intersections can be achieved in two different ways: the most proper designing of intersection geometry (geometric and topographic arrangements) and determining of signal timings considering traffic demands in intersection approaches (operational arrangement) [5-8]. Hence, effective signal management is a quite important factor 
to reduce the delay, fuel consumption, noise pollution, and exhaust emissions and to increase the intersection capacity and level of service of intersection [9-12].

In the absence of fluctuations in traffic demands in intersection approaches, the Optimum Fixed-Time Management (OFTM) system, which is widely used today, may be the right and appropriate choice to manage the traffic flows at intersections [13]. However, sports events, concerts, traffic accidents, bad weather conditions can sometimes cause short- or long-term fluctuations in traffic demands in some intersection approaches. In such cases, the operating efficiency of the OFTM system decreases, especially in intersection approaches where fluctuations in traffic demands exist. This situation may cause long-term delays, long queues, excessive fuel consumption, and exhaust emissions [1316]. It has been demonstrated in many studies by researchers that in the event of fluctuations in traffic demands, optimum fixed-time signal management systems cannot provide efficient results $[17,18]$.

For the last 60 years, a lot of studies have been conducted on signal control systems. Such studies are still under progress to improve the performances of the mentioned systems [19-21]. Since the last quarter of the 20th century, attempts have been dedicated to making these systems more effective in case of high traffic demands in signalized intersections and the objective has been to increase the operational efficiency further [22-26]. In recent years, there has been a significant increase in the number of studies on the signal management systems and control algorithms that take the instantaneous traffic flows into account. These systems may appear in different ways either optimization or created control algorithm-based systems $[27,28]$.

Traffic management systems operating based on any created control algorithm are referred to as vehicleactuated (traffic-actuated) signal management systems. Vehicle-actuated management systems determine the green and red signal timings according to the current dynamics of vehicle arrivals and queuing information obtained by detectors placed on the lanes in intersection approaches [28]. Because vehicleactuated signal management systems generally have positive effects on the intersection performance, many researchers have worked on this issue [26]. Some of these studies are summarized as follows.

Akçelik [22] proposed an approach to estimate the average green times and cycle time for vehicle-actuated management systems. He conducted an evaluation of the prediction of vehicle arrival headways and tried to determine the optimum cycle time. Trabia et al. [29] worked on fuzzy logic-based vehicle-actuated management systems. As a result of their study, they found that delays could be reduced by $10 \%$ using a fuzzy-based approach. Kim and Courage [30] proposed a maximum green time design method for a vehicleactuated management system that minimized delay. Guo et al. [31] developed two analytical models to optimize the maximum green times that were applied to vehicle-actuated management systems. They specified that these models could adjust maximum green time systematically and cyclically by adapting to the changes in traffic demands in intersections. Zheng et al. [32] worked on a control model that aimed to provide adaptive functionality of vehicle-actuated management systems. As a result of the study, it was found that the model had a great potential to improve the performance of the signalized network. Jiang et al. [33] developed a method to optimize the parameters of the vehicle-actuated signal management systems. In another study, Grether et al. [13] evaluated the vehicleactuated signal control strategy. As a result, they concluded that travel times could be significantly reduced using the vehicle-actuated management system, especially in the event of excessive increases in traffic demands. Swaminathan et al. [34] developed a vehicleactuated management model. According to analysis results, it was determined that the average delays could be reduced by $28 \%$ compared to the current situation with the developed control model. In a similar study, Guo and Ma [35] aimed to develop a new vehicleactuated signal control model, which resulted in lower average vehicle delays than both fixed-time and standard actuated control systems. Ribeiro and Simoes [36] used global optimization and complementarity to determine the green and red signal timings at each cycle for vehicle-actuated management systems. At the end of the analysis, it was concluded that the suggested methodology could be used for the determination of the green and red signal timings, as well as cycle lengths. Lee and Han [37] studied maximum green time settings for vehicle-actuated signal control at isolated intersections. They aimed to determine maximum green times using fuzzy logic approach, dynamically. As a result, it was determined that fuzzy logic was a useful approach to overcome the difficulty of setting a suitable maximum green time for any phase. In a different study, Wang et al. [38] investigated the green time extension for vehicle-actuated signal control. As a result, they found that the optimum critical headway value, which is an important parameter for green time extension, decreased with an increase in traffic demand and in some cases, this value may be more than 23 seconds as a common assumption. Promraksa et al. [39] studied vehicle-actuated signal management systems for reducing $\mathrm{CO}_{2}$ emission. At the end of the analysis, it was concluded that a fully-actuated management system could provide better and more encouraging results than the fixed-time and semiactuated management systems.

According to the previous studies, the selec- 
tion of the most proper design parameters (such as minimum critical headway, placement of detectors, minimum green signal timings, and maximum green signal timings) for the vehicle-actuated management systems has a direct and significant effect on the system performance. This study provides proper guides for designing an efficient vehicle-actuated signal control logic for signalized intersections. In the scope of the study, the selection of the most proper design parameters was evaluated, separately. Then, a new vehicle-actuated management system for a four-leg signalized intersection was developed in VISSIM Vehicle Actuated Programming (VISVAP). The efficiency of the developed system was tested on 20 different traffic scenarios considering different performance criteria (vehicle delay, fuel consumption, and exhaust emission) in VISSIM. To determine the success of the developed system, unlike the current studies in the literature, short- and long-term fluctuations in traffic demands in the signalized intersection approaches were also taken into account in the analysis. It is seen that the developed system can adapt to the fluctuations in traffic demands and enormously reduce the average vehicle delay, fuel consumption, and exhaust emission at the signalized intersection. Thus, it is determined that the developed system can be used for improving the performance of signalized intersections.

\section{Method}

\subsection{Vehicle-actuated management model for four-leg signalized intersections: VAM4}

In vehicle-actuated management, traffic flows at an intersection are managed based on the data and information from the detectors which are located in the intersection approaches [18]. Vehicle-actuated management systems can be classified in two ways as semi-actuated and fully-actuated. In semi-actuated management, only one or a few of the intersection approaches have detectors. In fully-actuated management, all intersection approaches have detectors and traffic flow data and information are provided from all approaches. In this type of management, green signal timings and cycle times are determined by considering the traffic demands detected. In fullyactuated management systems, the order of phases can be fixed or flexible. Furthermore, if there is no demand for a phase, that phase can be skipped directly. In vehicle-actuated management systems, the effective operation of an intersection generally depends on the following factors: minimum green times (sec), critical arrival headways of traffic flow, placement of detectors (detector locations), and maximum green times (sec). Therefore, choosing reasonable and appropriate values for these factors is crucial to improving the performance of the signalized intersections $[14,35]$. In this study, the performance of the vehicle-actuated signal management system (VAM4) developed for a fourleg signalized intersection was examined that included scenarios where short- or long-term fluctuations existed in traffic demands at intersection approaches. For this purpose, first, the control parameters and criteria related to the control algorithm of the proposed VAM4 were determined. In the analysis, considering the high traffic volumes, the minimum critical arrival headway is selected as approximately $2 \mathrm{sec}$. In this case, as long as the critical arrival headway determined by the detectors does not exceed $2 \mathrm{sec}$, the green signal timing of that phase is extended by $2 \mathrm{sec}$. When the current studies in the literature are examined, it can be seen that this value is generally selected between 1.5 and 4 sec $[14,40]$. Therefore, the selected green extension value (2 sec) was appropriate for the analysis. Besides, when the previous studies are examined carefully, there is no clear and precise information about the placement of detectors for vehicle-actuated management systems. However, the placement of the detectors was directly related to the traffic volume as a common practice in the literature $[14,15,40]$. According to previous studies, the detectors were placed generally $15 \mathrm{~m}$ to $45 \mathrm{~m}$ before the stop lines. However, there is no precise information about the placement of the detectors in the literature. In this study, the locations of the detectors were determined by trial and error for each traffic scenario. According to the results obtained by trial and error, the relationship between the distance of the detectors to the stop line at the intersection approaches and the average delay was determined, as given in Figure 1. This relationship is similar to that depicted by Bullen [14].

When the previous studies are examined, the minimum green time is generally selected as $4-5 \mathrm{sec}$ or above depending on the distance of the detector to the stop line $[14,15]$. As mentioned before, especially when the traffic volumes in intersection approaches are high, the distance of the detectors to the stop line can be up to 45 meter. For this reason, the minimum green time value must be determined considering locations (placements) of the detectors in the intersection ap-

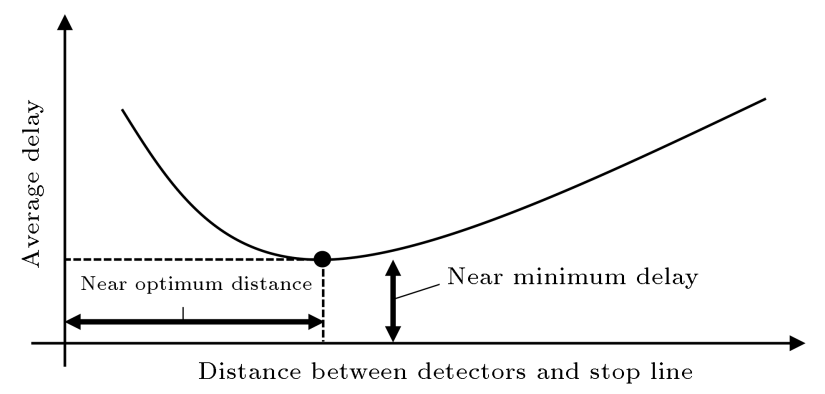

Figure 1. The relation between average vehicle delay and the placement of detectors. 
Table 1. Minimum green times for different detector locations.

\begin{tabular}{lccccccc}
\hline \multicolumn{1}{c}{ Option } & O-1 & O-2 & O-3 & O-4 & O-5 & O-6 & O-7 \\
\hline Distance between detectors and stop line (m) & 15 & 20 & 25 & 30 & 35 & 40 & 45 \\
Minimum green times (sec) & 5 & 7 & 9 & 11 & 13 & 15 & 17 \\
\hline
\end{tabular}

Note: O-1, O-2,, O-7 show the options of distance between detector and stop line.

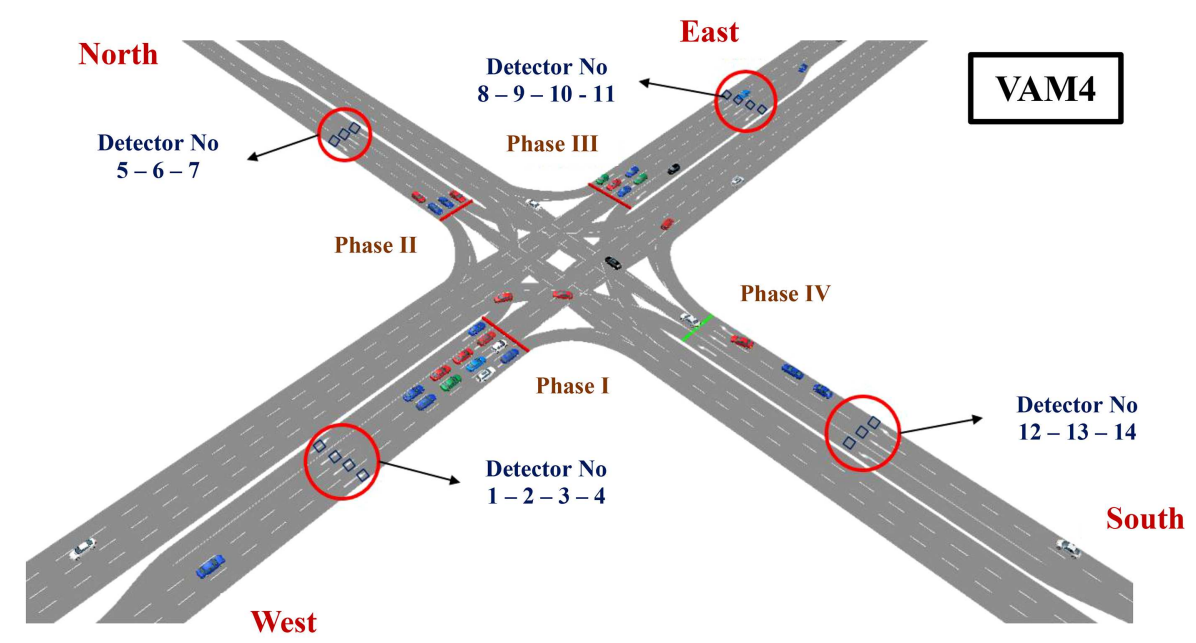

Figure 2. Vehicle-actuated management application at a four-leg signalized intersection in VISSIM simulation program.

proaches. The determined minimum green time must allow clearing of the queues at intersection approaches. Depending on the locations of the detectors, the minimum green times for the vehicle-actuated management systems can be calculated using Eq. (1) [15]:

$$
G_{\min }=t_{L}+\left[h \times \text { integer }\left(\frac{l}{e}\right)\right]
$$

where:

$G_{\text {min }} \quad$ Minimum green time (sec)

$t_{L} \quad$ Assumed start-up lost time (sec)

$h \quad$ Assumed saturation headway (sec)

$l \quad$ Distance between detectors and stop line $(\mathrm{m})$

$e \quad$ Distance between stored vehicles (average 6-7 m)

In the scope of this study, minimum green times are computed through Eq. (1). Depending on the distance between detectors and stop line, the obtained minimum green times are presented in Table 1.

According to previous studies, the maximum green time for vehicle-actuated management systems is generally selected between 45 and $60 \mathrm{sec}$ [41]. In this study, the maximum green time of each phase is selected as $60 \mathrm{sec}$ and this value is used in the analysis. General information about the proposed VAM4 for the four-leg signalized intersection model is shown in Figure 2 .
Based on Figure 2, the modeled four-leg signalized intersection has a total of 14 detectors for 14 lanes (one detector for each lane). These detectors are used for both detecting the queuing in intersection approaches and determining the vehicle arrival headways. In the developed VAM4 model, it is assumed that the modeled four-leg signalized intersection is applied with four phases. Right of way for each intersection approach is provided in separate phases. Right of ways for the West, North, East, and South intersection approaches are provided in Phase I, Phase II, Phase III, and Phase IV, respectively. Besides, in the developed VAM4 model, when excitation is not detected from the detectors which are in one of the intersection approaches, phase transition can be actualized (the order of phases may change). The simulation period for the analysis is determined as $3600 \mathrm{sec}$. The flow chart of the developed VAM4 control logic is presented in Figure 3.

\subsection{Traffic scenarios and fluctuations in traffic demands}

In the scope of this study, first, a movement directionbased reference demand matrix has been created considering the four-leg signalized intersection model shown in Figure 2. This created reference demand matrix for the analysis is given in Table 2 .

In the next step, a total of 20 different traffic scenarios are created by using the reference demand matrix given in Table 2 for the modeled four-leg signalized intersection. For each created scenario, movement 


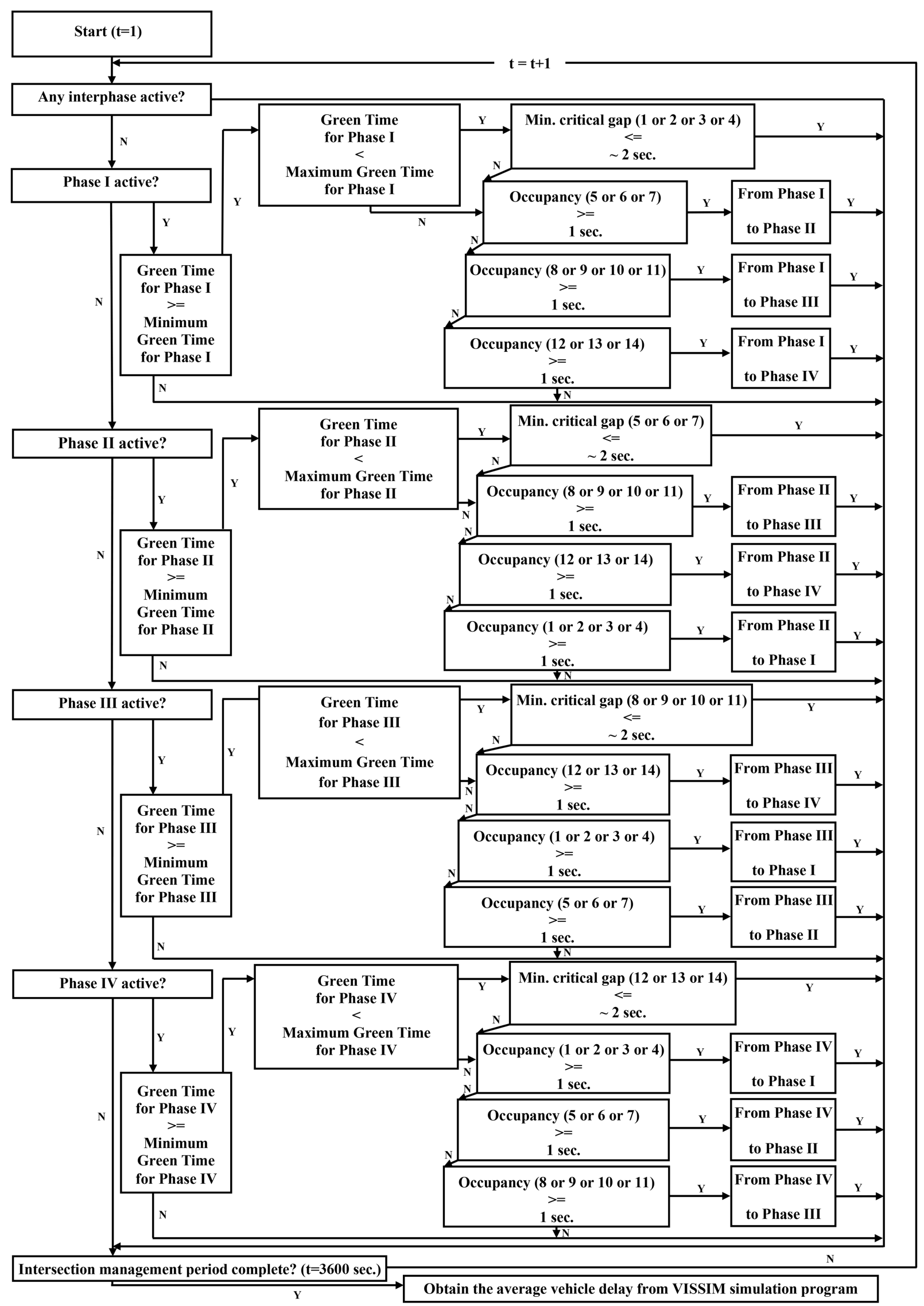

Figure 3. The flow chart of vehicle-actuated control logic created with Vehicle Actuated Program (VAP). 
Table 2. Reference demand matrix created for analysis studies.

\begin{tabular}{|c|c|c|c|c|c|c|c|c|c|}
\hline \multicolumn{5}{|c|}{ Volumes (veh/hr) } & \multicolumn{5}{|c|}{ Flow rates } \\
\hline $\begin{array}{c}\text { Intersection } \\
\text { approach } \\
\text { (O-D) }\end{array}$ & West & North & East & South & $\begin{array}{c}\text { Intersection } \\
\text { approach } \\
(\text { O-D }) \\
\end{array}$ & West & North & East & South \\
\hline West & - & 200 & 700 & 100 & West & - & 0.200 & 0.700 & 0.100 \\
\hline North & 150 & - & 100 & 150 & North & 0.375 & - & 0.250 & 0.375 \\
\hline East & 600 & 100 & - & 150 & East & 0.706 & 0.118 & - & 0.176 \\
\hline South & 200 & 250 & 200 & - & South & 0.308 & 0.384 & 0.308 & - \\
\hline
\end{tabular}

West intersection approach: $1000 \mathrm{veh} / \mathrm{hr}$

North intersection approach: $400 \mathrm{veh} / \mathrm{hr}$

Total traffic flow at intersection: 2900

East intersection approach: $850 \mathrm{veh} / \mathrm{hr}$

South intersection: $650 \mathrm{veh} / \mathrm{hr}$

direction-based traffic volumes exhibited an increase or decrease based on the reference demand matrix. Besides, some of the movement direction-based traffic volumes are constant in some scenarios. The increase and decrease rates of the movement direction-based traffic volumes for all scenarios are shown in Figure 4.

According to Figure 4, when the scenario number increases, general increase trends are seen in movement direction-based traffic volumes. Therefore, the total traffic volumes at the intersection increase when the scenario number increases, as shown in Figure 5. According to Figure 5, the created traffic scenarios are divided into four groups in terms of total traffic volumes at the intersection. According to their demand levels, these groups are named as low, moderate, high, and very high. When the hourly total traffic demand ranges between 2000 veh. and 2500 veh., the demand is considered to be low. If the hourly total traffic demand is between 2500 veh. and 3000 veh., it can be said that the demand is moderate. When the hourly total

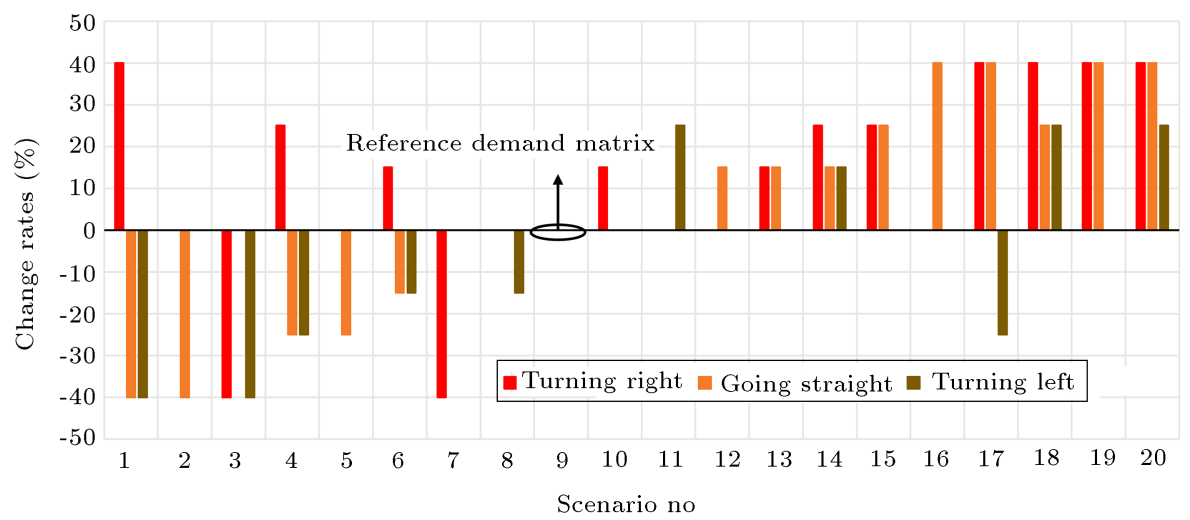

Figure 4. The change rates of movement direction-based traffic volumes for created scenarios.

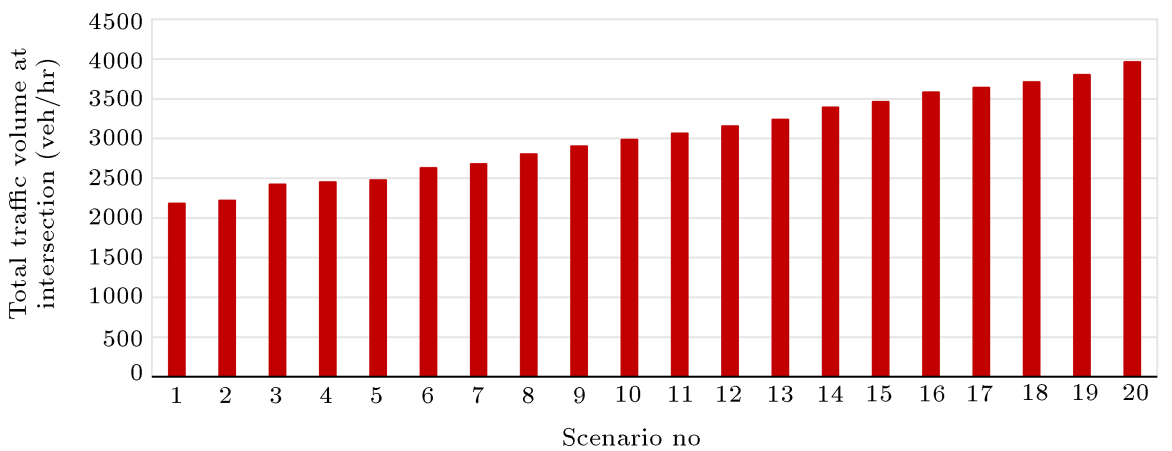

Figure 5. Hourly total traffic volumes for all traffic scenarios. 
traffic demand is between 3000 veh. and 3500 veh., the demand is regarded as high. Finally, if the hourly total traffic demand is between 3500 veh. and 4000 veh., it can be said that the demand is very high. Thus, the performance of the VAM4 model developed for a four-leg signalized intersection could be evaluated for the cases of low, moderate, high, and very high traffic demands, separately.

As it is known, in the VISSIM simulation program, the time intervals when the fluctuations in traffic demands occur and the quantities (proportions) of the fluctuations at these time intervals can be determined by the users. Thus, as a result of short- or long-term fluctuations arising for such reasons as concerts, sports events, traffic accidents, adverse weather conditions, changes that occur in the performance of intersection can be analyzed in VISSIM.

As mentioned above, this study aims to examine the performance and effectiveness of the developed VAM4 in case of fluctuations with variable quantities at variable time intervals for traffic demands in different intersection approaches. To this end, sample cases related to the quantities of the fluctuations in traffic demands and the time intervals when the fluctuations occur in traffic demands are created for each traffic scenario. The created sample cases are presented in Figure 6. In Figure 6, for each traffic scenario, the time intervals when the fluctuations occur in traffic demands in different intersection approaches and the quantities of fluctuations during 60 minutes of the analysis period can be seen in detail. As an example, for Scenario 6, it is assumed that the fluctuations in traffic demands occur twice in the West and North approaches and only once in the East approach during 60 minutes of the analysis period. Besides, for Scenario 6, the following matters can be said about the quantities of fluctuations and the time intervals when the fluctuations occur in traffic demands:

- It is assumed that approximately $33 \%$ of the vehicles in the west approach arrive at the intersection between the 20th and 33rd minutes, and approximately $28 \%$ arrive at the intersection between the 47 th and 60th minutes;

- It is assumed that approximately $22 \%$ of the vehicles in the north approach arrive at the intersection between the 20th and 27 th minutes and $22 \%$ arrive at the intersection between the 40th and 47th minutes;

- It is assumed that approximately $50 \%$ of the vehicles in the east approach arrive at the intersection between the 13 th and $33 \mathrm{rd}$ minutes.

\section{Analysis}

Webster, Highway Capacity Manual (HCM) and Akcelik methods are the most used delay calculation ap- proaches to predicting the average vehicle delay which occurs in signalized intersections [20,40,42]. While the Webster and HCM methods are based on the phase-related design, the Akcelik method is based on the movement-related design. In the scope of the study, following a delicate examination of the modeled intersection, it was seen that all lanes in intersection approaches were designed based on the traffic flows' movement directions. Thus, the Akcelik delay model with the aim of movement-related design was used for optimizing the signal timings in this study. According to the Akcelik method, the approximate value of total delay for a movement can be calculated using Eq. (2) [42]:

$$
D=\frac{q C \times(1-u)^{2}}{2 \times(1-y)}+N_{o} x
$$

where:

$\begin{array}{ll}D & \text { Total delay }(\mathrm{sec}) \\ q & \text { Flow }(\mathrm{veh} / \mathrm{sec}) \\ C & \text { Cycle time }(\mathrm{sec}) \\ q C & \begin{array}{l}\text { Average number of arrivals of vehicles } \\ \text { per cycle }\end{array} \\ u & \text { Green time ratio }(g / C) \\ y & \text { Flow ratio }(q / s) \\ N_{o} & \text { Average overflow queue }(\mathrm{veh}) \\ x & \text { Degree of saturation }(q / Q)(\mathrm{veh}) .\end{array}$

In the signalized intersection approach, to predict the overflow queues for both undersaturated $(x<1)$ and oversaturated $(x>1)$ conditions, the following Eq. (3), which was developed by Akcelik, could be used:

$$
N_{o}=\left\{\begin{array}{cc}
\frac{Q T_{f}}{4}\left(z+\sqrt{z^{2}+\frac{12\left(x-x_{o}\right)}{Q T_{f}}}\right), & x \geq x_{o} \\
0, & x<x_{o}
\end{array}\right\}
$$

where:

$N_{o} \quad$ Average overflow queue (veh)

$Q \quad$ Capacity in vehicle in per hour (veh/hr)

$T_{f} \quad$ Flow period

$Q T_{f} \quad$ Maximum number of vehicles discharged during the interval $T_{f}$

$x \quad$ Degree of saturation $(q / Q)$

z $\quad x-1$

$x_{0} \quad$ The degree of saturation below which the average overflow queue is approximately zero

The degree of saturation below which the average overflow queue is approximately zero $\left(x_{o}\right)$ can be 


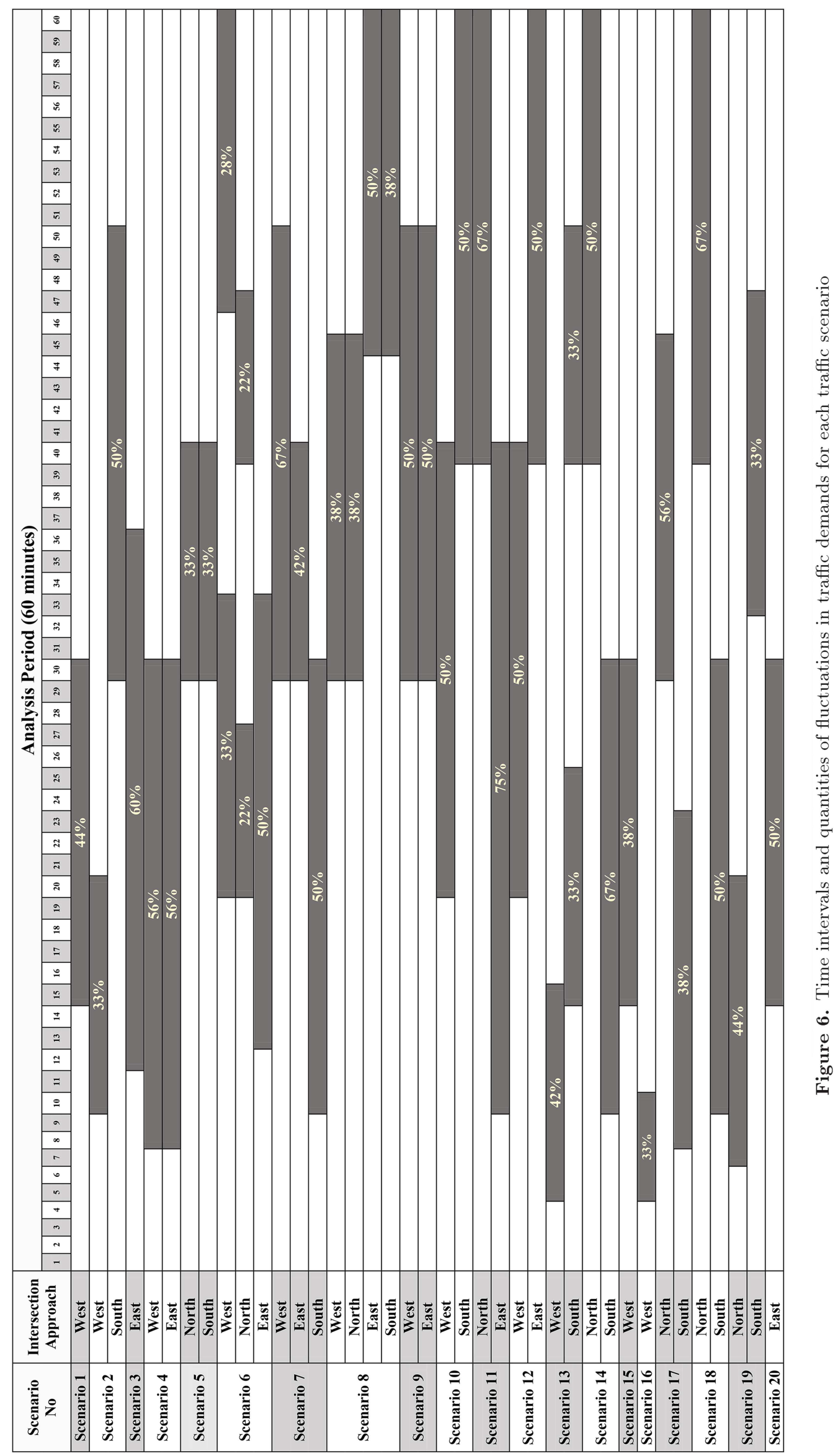


Table 3. The objective function, the decision variables, and the set of constraints for the signal timing optimization problem.

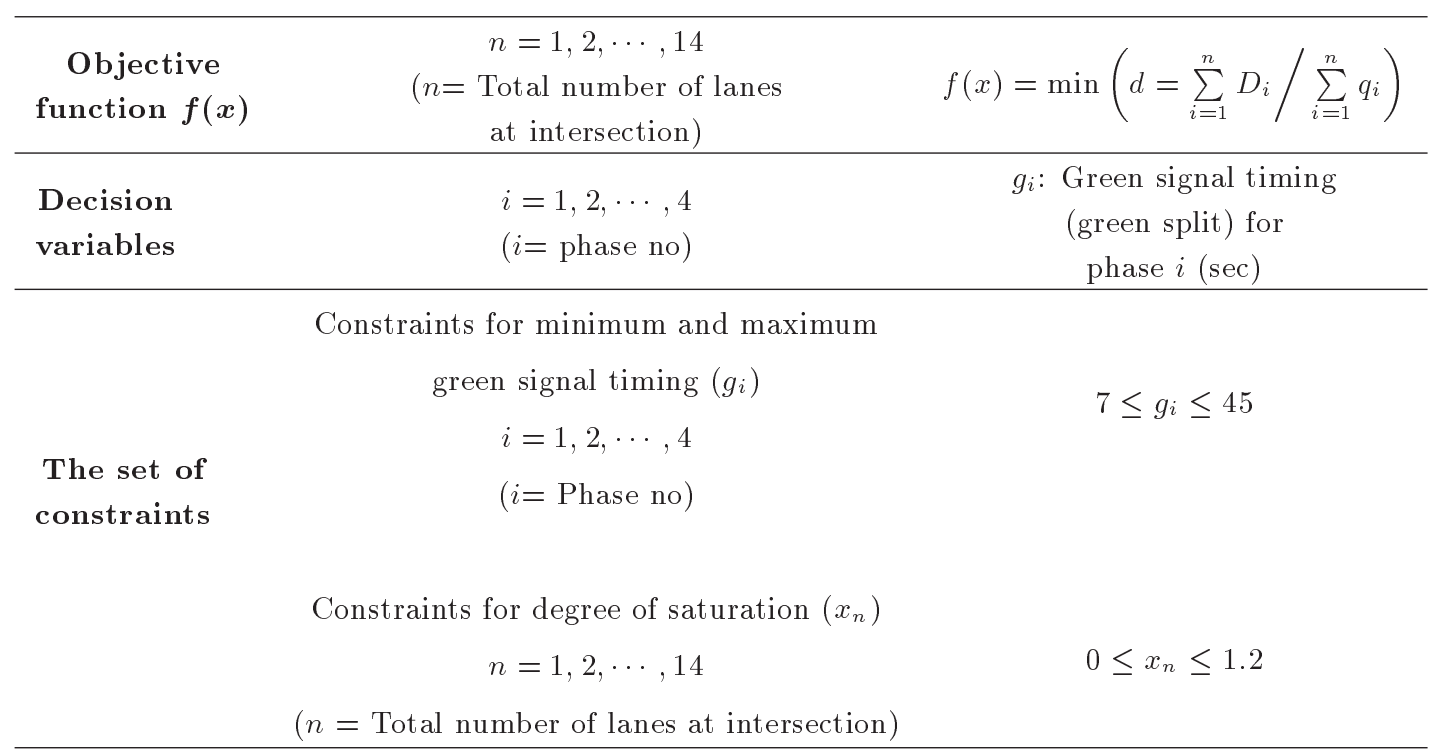

calculated by Eq. (4):

$$
x_{o}=0.67+\frac{s g}{600},
$$

where $s$ is saturation flow (veh/sec) and $g$ is effective green time (sec). Average vehicle delay can be calculated by Eq. (5):

$$
d=\frac{D}{q}
$$

where $D$ is total delay (sec) and $q$ is flow (veh). According to the analysis findings, their objective was to determine the effectiveness of VAM4, which was created in VISVAP. Therefore, first, it was assumed that the modeled signalized intersection was managed with an optimum fixed-time signal control system and it operated through four phases. The signal timings were optimized by minimizing average vehicle delay at the intersection. The objective function $f(x)$, the decision variables, and the set of constraints for the signal timing optimization problem are shown in Table 3 .

According to Table 3, for the modeled intersection, the optimization problem consists of 1 objective function, 4 decision variables, and 18 constraints. When the previous studies were investigated carefully, it was seen that green signal timings for each phase should be within a certain range [43]. Thus, green signal timings were constrained between $7 \mathrm{sec}$ and $45 \mathrm{sec}$ considering the previous studies in the literature $[43,44]$. In addition, the degree of saturation for each lane was constrained with a maximum of 1.2. Differential Evolution (DE) algorithm, which is a powerful and simple meta-heuristic optimization algorithm, is preferred to solve the signal timing optimization problem [45-49]. A signal timing optimization program was developed in MATLAB for this purpose. In the case of the created traffic scenarios, the obtained signal timings and average vehicle delays are given in Table 4 in detail.

Because all of the scenarios created in the scope of the study are analyzed in VISSIM, Akcelik average vehicle delay results and average vehicle delay results obtained from VISSIM should be similar to each other for the same scenarios. Rational and suitable evaluation cannot be possible, otherwise. Due to the differences between the results, firstly, an evaluation area was established considering the points which are $100 \mathrm{~m}$ away from all approach stop lines. Then, the driving behaviors and safety factors in VISSIM software were revised considering the results obtained from Akcelik delay equation. Thus, average vehicle delay results for each scenario are likened to each other. For the created scenarios, the comparison between the average vehicle delay values is shown in Table 5 .

As can be seen from Table 5 , for created scenarios, the differences are generally below about $5 \%$. The accuracy of the simulation is determined by using the sum of squared error value [50]. This value is calculated as 33.56. These results show that the VISSIM can provide similar average delay values using the Akcelik delay equation and be used for analysis studies. The average vehicle delay values, which are obtained using VISSIM and the Akcelik delay equation, are shown in Figure $7(\mathrm{a})$. The difference in the delay percentage obtained by Akcelik and VISSIM is also given in Figure $7(\mathrm{~b})$.

After the completion of the revision process in the VISSIM simulation program, to determine the 
Table 4. Optimum signal timings and average vehicle delays for the created traffic scenarios.

\begin{tabular}{|c|c|c|c|c|c|c|c|c|c|c|c|c|c|c|c|}
\hline 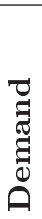 & 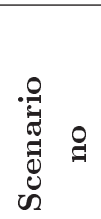 & 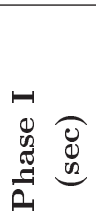 & 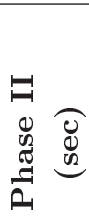 & 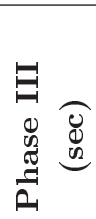 & 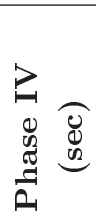 & 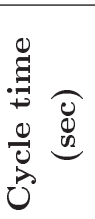 & 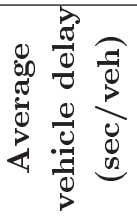 & 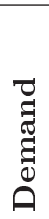 & 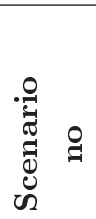 & 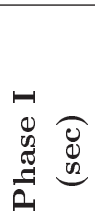 & 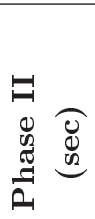 & 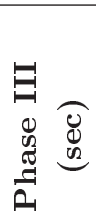 & 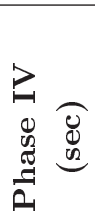 & 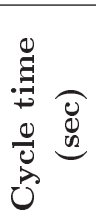 & 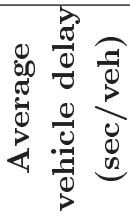 \\
\hline \multirow{5}{*}{ مִ } & 1 & 10 & 9 & 9 & 12 & 60 & 25.00 & \multirow{5}{*}{$\stackrel{50}{\stackrel{50}{80}}$} & 11 & 19 & 9 & 17 & 14 & 79 & 34.00 \\
\hline & 2 & 9 & 7 & 8 & 9 & 53 & 20.82 & & 12 & 25 & 11 & 22 & 17 & 95 & 43.82 \\
\hline & 3 & 19 & 8 & 16 & 13 & 76 & 33.25 & & 13 & 24 & 11 & 21 & 17 & 93 & 44.63 \\
\hline & 4 & 13 & 9 & 11 & 11 & 64 & 26.89 & & 14 & 25 & 12 & 22 & 18 & 97 & 45.55 \\
\hline & 5 & 12 & 7 & 10 & 9 & 58 & 23.60 & & 15 & 31 & 14 & 27 & 22 & 114 & 55.59 \\
\hline \multirow{5}{*}{ 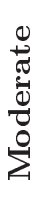 } & 6 & 14 & 8 & 12 & 11 & 65 & 28.32 & \multirow{5}{*}{ 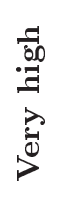 } & 16 & 45 & 19 & 39 & 31 & 154 & 78.83 \\
\hline & 7 & 19 & 8 & 16 & 13 & 76 & 32.84 & & 17 & 45 & 20 & 39 & 31 & 155 & 82.37 \\
\hline & 8 & 19 & 9 & 17 & 13 & 78 & 33.30 & & 18 & 31 & 15 & 27 & 22 & 115 & 57.56 \\
\hline & $9(\mathrm{R})$ & 19 & 9 & 16 & 13 & 77 & 33.20 & & 19 & 45 & 20 & 39 & 31 & 155 & 81.21 \\
\hline & 10 & 18 & 9 & 16 & 13 & 76 & 34.51 & & 20 & 45 & 20 & 39 & 31 & 155 & 80.26 \\
\hline
\end{tabular}

Note: Phase I: West; Phase II: North; Phase III: East; Phase IV: South.

Inter green time: $5 \mathrm{sec}$.

(R): Reference demand.

Table 5. Scenario-based comparison of average vehicle delay values (sec/veh).

\begin{tabular}{|c|c|c|c|c|c|c|c|c|c|c|c|c|c|c|c|}
\hline & $\stackrel{\circ}{z}$ & & & & $\stackrel{g}{z}$ & & & & 1 & & & & = & & \\
\hline 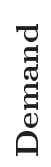 & . & 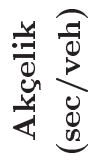 & 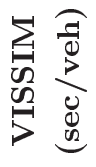 & 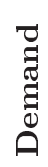 & 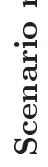 & 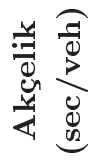 & 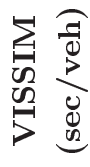 & 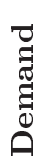 & 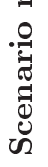 & 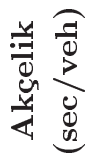 & 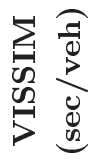 & 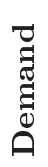 & 串 & 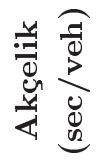 & 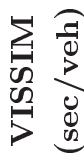 \\
\hline \multirow{5}{*}{ فِ } & 1 & 25.00 & 25.51 & \multirow{5}{*}{ 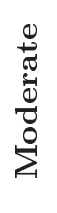 } & 6 & 28.32 & 27.52 & \multirow{5}{*}{ } & 11 & 34.00 & 34.47 & \multirow{5}{*}{$\begin{array}{l}\frac{1}{80} \\
\frac{1}{3} \\
20 \\
0 \\
0\end{array}$} & 16 & 78.83 & 82.44 \\
\hline & 2 & 20.82 & 21.68 & & 7 & 32.84 & 33.38 & & 12 & 43.82 & 42.32 & & 17 & 82.37 & 84.21 \\
\hline & 3 & 33.25 & 33.91 & & 8 & 33.30 & 31.74 & & 13 & 44.63 & 42.73 & & 18 & 57.56 & 56.16 \\
\hline & 4 & 26.89 & 26.60 & & 9 & 33.20 & 32.23 & & 14 & 45.55 & 44.82 & & 19 & 81.21 & 79.88 \\
\hline & 5 & 23.60 & 23.76 & & 10 & 34.51 & 34.94 & & 15 & 55.59 & 56.10 & & 20 & 80.26 & 79.55 \\
\hline
\end{tabular}

effectiveness of VAM4, the created vehicle actuated signal management control algorithm is tested on all traffic scenarios. At this stage, firstly, the most proper placements of detectors for each scenario were determined through trial and error. For Scenarios 5 and 17 , the average vehicle delay values that were obtained depending on the detector placement are given in Figure 8.

As seen in Figure 8, a comprehensive study was carried out to determine the most proper placement of the detectors. Because the distance between detectors and stop lines varies from $15 \mathrm{~m}$ to $45 \mathrm{~m}$, detectors

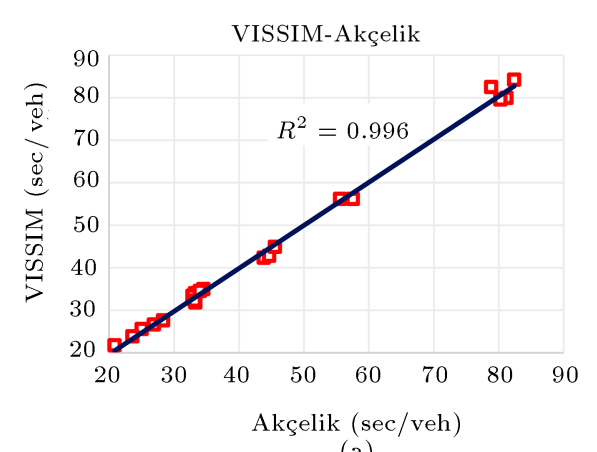

(a)

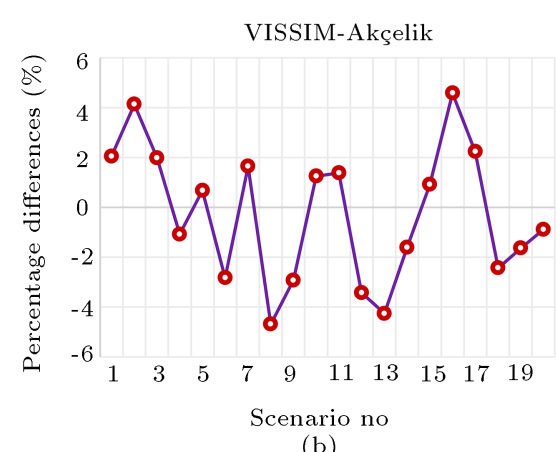

(b)

Figure 7. The created scenarios: (a) The comparison of average vehicle delay values and (b) the percentage (\%) differences of average vehicle delay values. 


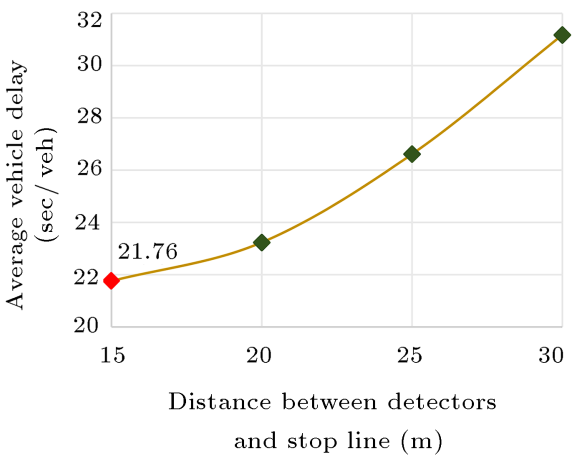

(a)

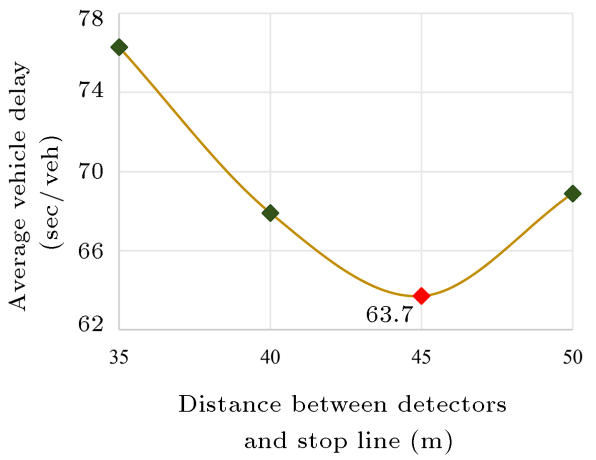

(b)

Figure 8. The effect of detector placements on average vehicle delay: (a) Scenario 5 and (b) Scenario 17.

must be placed within this range in all intersection approaches. At this stage, the created scenarios were analyzed based on different distances between detectors and stop lines. At the end of the analyses, the distance that corresponds to the minimum average vehicle delay value was considered as the most proper distance between detectors and stop lines. Near optimum detector placements (distances) which are obtained from the analysis for all created scenarios are presented in Table 6.

As can be seen from Table 6, when the total traffic volume at the intersection increases, the distance between detectors and stop line also exhibits an increase. While the total traffic demand at the intersection is low or moderate, near optimum distances between detectors and stop line vary in the range of $15 \mathrm{~m}$ and 25 $\mathrm{m}$, in general. Besides, while the total traffic demand at the intersection is high or very high, near optimum distances between detectors and stop line vary in the range of 30 to $45 \mathrm{~m}$.

\section{Results}

Upon determining the most proper placements of detectors for all created scenarios, two different types of traffic management approaches were evaluated separately considering whether the fluctuations in traffic demands exist or not for each scenario. These four different cases taken into account for the analysis can be summarized as follows:

- Optimum Fixed-Time Management/Fluctuations do not exist in traffic demands (OFTM/NotFluctuated): In this case, fluctuations do not exist in traffic demands. Movement-based traffic volumes and optimum signal timings are transferred

Table 6. Optimum detector placements for the created scenarios.

\begin{tabular}{|c|c|c|c|c|c|c|c|c|c|}
\hline \multirow[b]{2}{*}{$\begin{array}{c}\text { Scenario } \\
\text { no }\end{array}$} & \multicolumn{4}{|c|}{$\begin{array}{c}\text { Distance between detectors } \\
\text { and stop line }(\mathrm{m})\end{array}$} & \multirow[b]{2}{*}{$\begin{array}{c}\text { Scenario } \\
\text { no }\end{array}$} & \multicolumn{4}{|c|}{$\begin{array}{c}\text { Distance between detectors } \\
\text { and stop line }(\mathrm{m})\end{array}$} \\
\hline & $\begin{array}{c}\text { West } \\
\text { approach }\end{array}$ & $\begin{array}{c}\text { North } \\
\text { approach }\end{array}$ & $\begin{array}{c}\text { East } \\
\text { approach }\end{array}$ & $\begin{array}{c}\text { South } \\
\text { approach }\end{array}$ & & $\begin{array}{c}\text { West } \\
\text { approach }\end{array}$ & $\begin{array}{c}\text { North } \\
\text { approach }\end{array}$ & $\begin{array}{c}\text { East } \\
\text { approach }\end{array}$ & $\begin{array}{c}\text { South } \\
\text { approach }\end{array}$ \\
\hline 1 & 15 & 15 & 15 & 15 & 11 & 20 & 20 & 20 & 20 \\
\hline 2 & 15 & 15 & 15 & 15 & 12 & 30 & 30 & 30 & 30 \\
\hline 3 & 15 & 15 & 15 & 15 & 13 & 30 & 30 & 30 & 30 \\
\hline 4 & 15 & 15 & 15 & 15 & 14 & 35 & 35 & 35 & 35 \\
\hline 5 & 15 & 15 & 15 & 15 & 15 & 45 & 45 & 45 & 45 \\
\hline 6 & 15 & 15 & 15 & 15 & 16 & 45 & 45 & 45 & 45 \\
\hline 7 & 20 & 20 & 20 & 20 & 17 & 45 & 45 & 45 & 45 \\
\hline 8 & 20 & 20 & 20 & 20 & 18 & 45 & 45 & 45 & 45 \\
\hline 9 & 25 & 25 & 25 & 25 & 19 & 45 & 45 & 45 & 45 \\
\hline 10 & 20 & 20 & 20 & 20 & 20 & 45 & 45 & 45 & 45 \\
\hline
\end{tabular}


to VISSIM. At the end of the analysis, average vehicle delay values for each scenario were obtained. Obtained results can be seen in Table 5;

- Vehicle-Actuated Management/Fluctuations do not exist in traffic demands (VAM4/ Not-Fluctuated): In the second case, fluctuations do not exist in traffic demands. All of the scenarios were analyzed considering the VAM4 model, which is created in VISVAP;

- Optimum Fixed-Time Management/Fluctuations exist in traffic demands (OFTM/ Fluctuated): In the third case, fluctuations exist in traffic demands for each scenario (in Figure 6). The only difference between this case and the first case is the fluctuations existing in traffic demands. Movementbased traffic volumes and total traffic volumes are the same for the first and third cases. In this case, the investigation of the success of Optimum Fixed-Time Management (OFTM) was aimed for fluctuated traffic demands;

- Vehicle-Actuated Management/Fluctuations exist in traffic demands (VAM4/ Fluctuated): In the fourth case, fluctuations exist in traffic demands for each scenario (in Figure 6). The only difference between this case and the second one is the fluctuations in demands. Movement-based traffic volumes and total traffic volumes are the same for the second and fourth cases. In this case, the success of VAM4 in managing the fluctuating traffic demands was investigated.

At the end of the analysis that was conducted based on the four different cases described above, average vehicle delay-fuel consumption and exhaust emission $\left(\mathrm{CO}+\mathrm{NO}_{x}\right)$ values were obtained for each scenario. Obtained average vehicle delay, fuel consumption, and exhaust emission values are shown in Figure 9(a), (b), and (c), respectively.

As seen in Figure 9, especially in case of fluctuated traffic demands, the effectiveness of the optimum fixedtime signal management system decreases dramatically. Besides, the average vehicle delays, fuel consumptions, and exhaust emissions can be significantly reduced by implementing vehicle-actuated signal control at the intersection. For Scenario 3, at the time interval when the fluctuations occur in traffic demands, the sample intersection views which are obtained from VISSIM in case of implementing the OFTM or/and vehicle actuated management are presented in Figure 10.

In Figure 10, for Scenario 3, at a time interval when fluctuations occur in the traffic demands, sample intersection views in case of implementing the different types of management approaches are shown. As shown in Figure 6, the fluctuations in the traffic demands for Scenario 3 occur in between the 12th and 36th minutes. Therefore, simulation views are taken in the 25 th minutes $(1475 \mathrm{sec})$ of the simulation. According to Figure 10, in case of implementing optimum-fixed time traffic management at the modeled signalized intersection, excessive queuing (queues) is seen in the intersection approaches where fluctuations in traffic demands occur (Figure 10(a)). Upon examining Figure 10(b) carefully and in case of implementing vehicle-actuated management instead of OFTM at the modeled intersection, queuing (queues) in intersection approaches where fluctuations in traffic demands occur can be significantly reduced. Thus, the performance of the intersection can also be improved in this way.

When the fluctuations do not exist in traffic demands, although vehicle-actuated signal management systems have more advantages than optimum fixedtime signal management systems, lower success rates will follow. For the sample scenario (Scenario 3) which is shown in Figure 10, sample intersection views at the same time intervals in case of implementing the OFTM and vehicle-actuated management are presented in Figure 11. In Figure 11, for Scenario 3, when the fluctuations do not exist in the traffic demands, sample intersection views at the same time interval in case of implementing different types of management approaches are shown. Based on Figure 11, when the fluctuations do not exist in traffic demands, excessive queuing is not seen in the intersection approaches in case of implementing both OFTM and vehicle-actuated management. However, more queuing occurs in case of implementing OFTM (in Figure 11(a)) than in case of implementing vehicle-actuated management (in Figure 11(b)). Based on Figure 11, queuing in intersection approaches can be reduced in case of implementing vehicle-actuated management. As a result, it was concluded that simulation views would be compatible with obtained performance results. The simulation views support and verify the obtained results.

For the created traffic scenarios, reduction rates (success rates) were evaluated separately considering whether fluctuations in traffic demands exist or not. In case of implementing vehicle-actuated management instead of OFTM, the obtained reduction rates (success rates) for each performance criterion are presented in Figure 12.

When Figure 12 is examined carefully, the obtained results can be summarized as follows:

- For the fluctuated traffic demands, when the total traffic demand at the intersection is low, moderate, or high, average vehicle delay can be reduced in the range of $20 \%$ and $60 \%$ and fuel consumption and exhaust emission can be reduced between about $15 \%$ and $40 \%$;

- For the fluctuated traffic demands, when the total traffic demand at the intersection is very high, the 

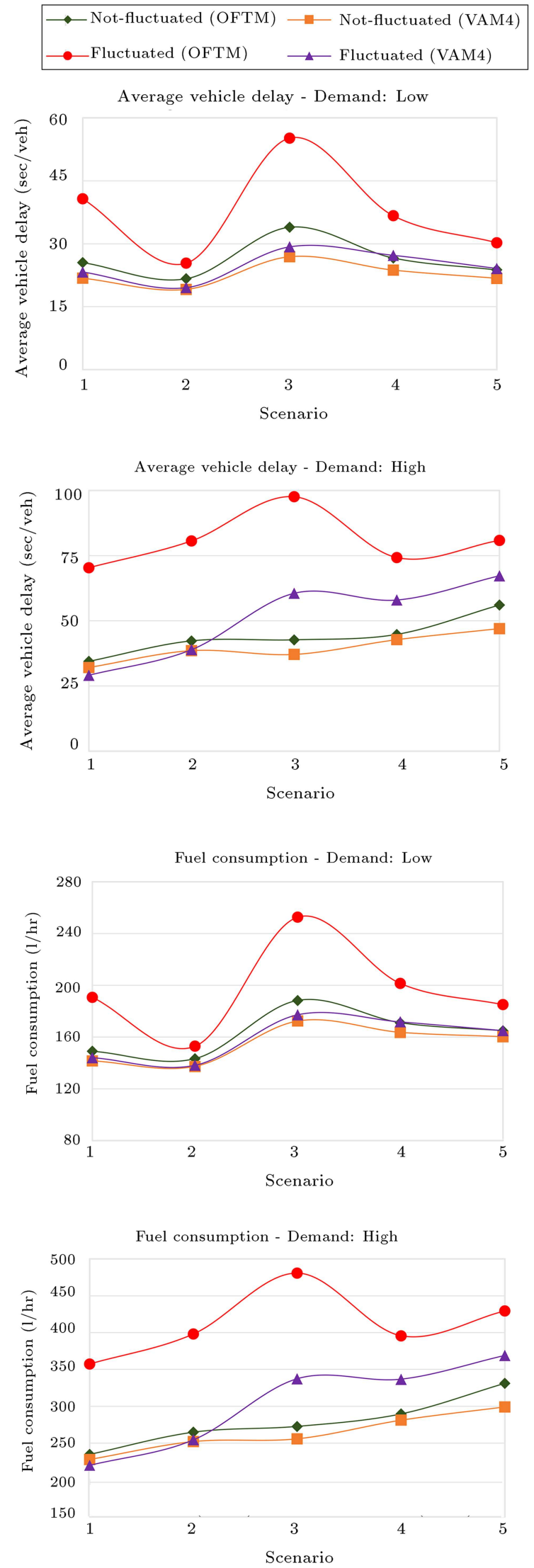

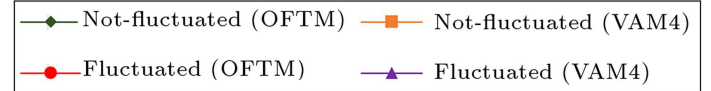

Average vehicle delay - Demand: Moderate
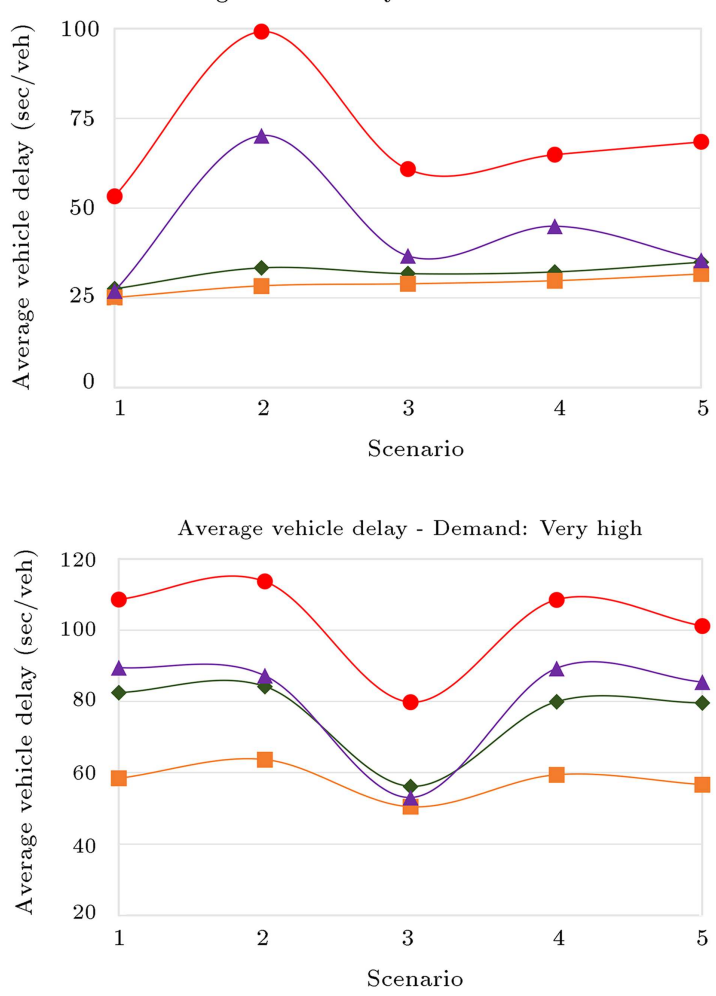

(a)
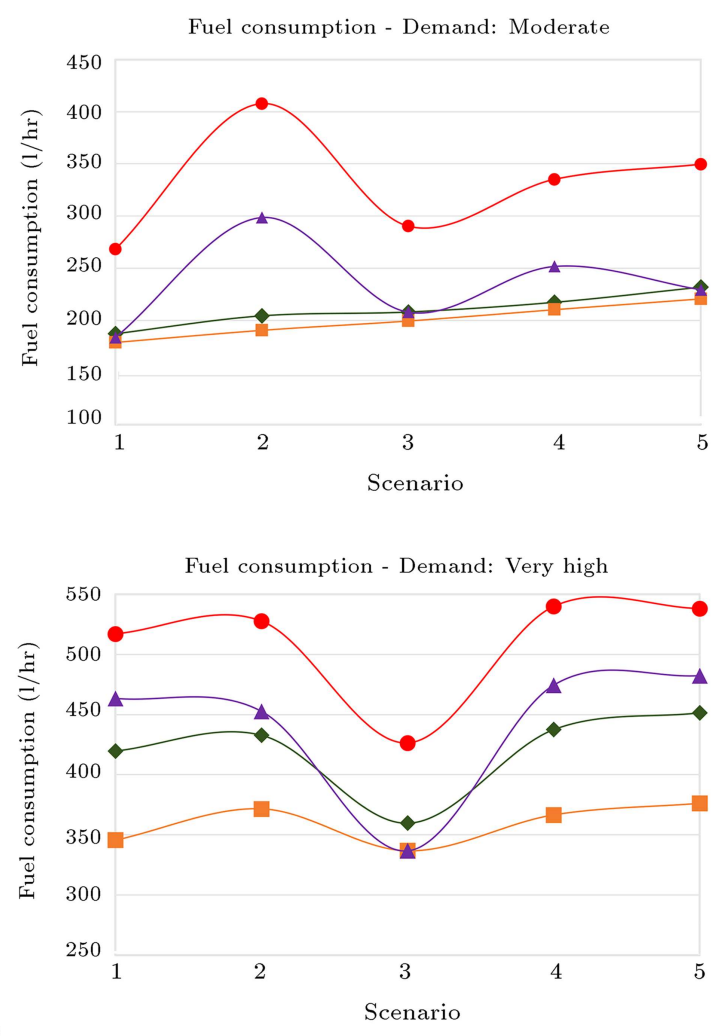

Figure 9. (a) Obtained average vehicle delay results, (b) obtained fuel consumption results, and (c) obtained exhaust emission results for the created scenarios at the end of the analysis. 

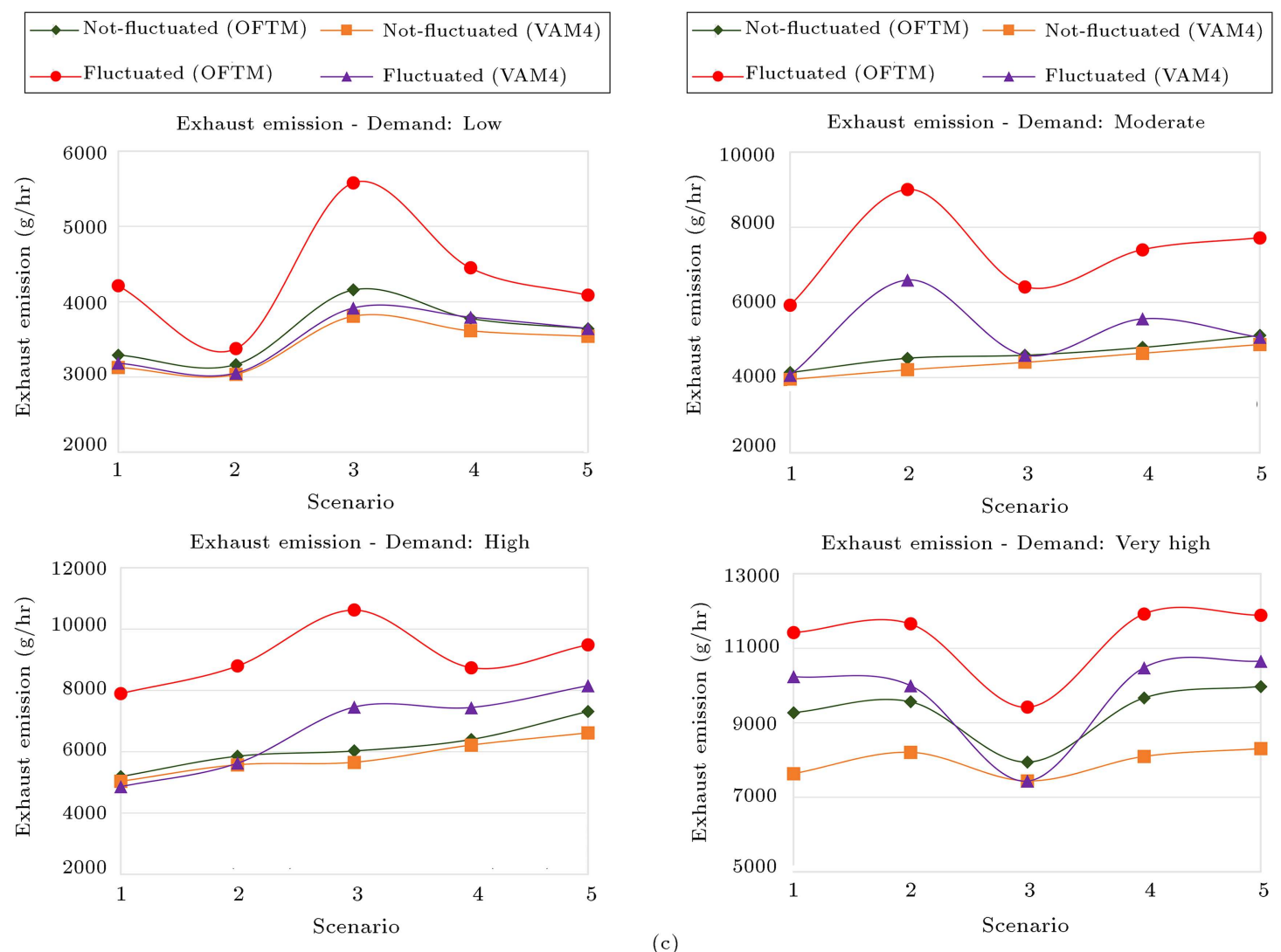

Figure 9. (a) Obtained average vehicle delay results, (b) obtained fuel consumption results, and (c) obtained exhaust emission results for the created scenarios at the end of the analysis (continued).

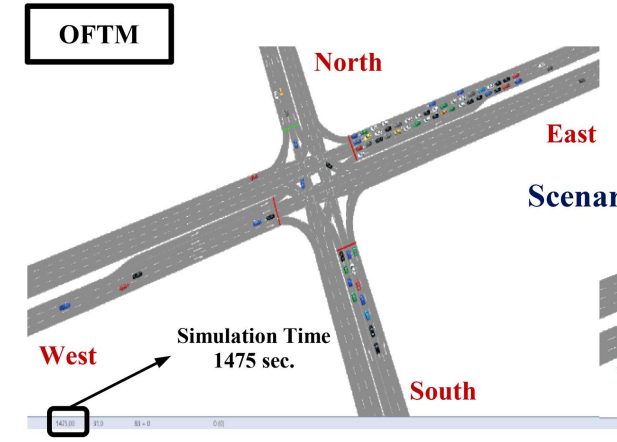

(a)

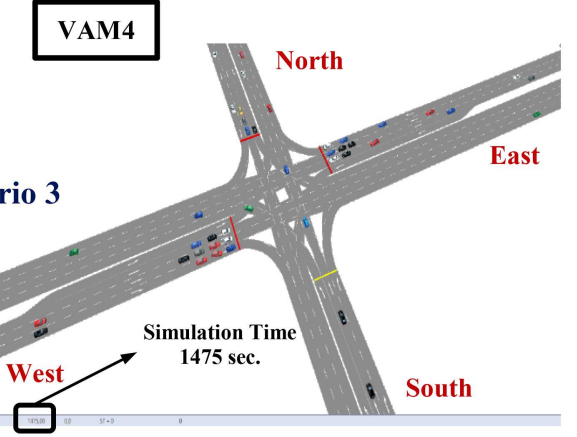

(b)

Figure 10. Scenario 3 at the time interval when the fluctuations occur in traffic demands. The sample intersection view in case of implementing: (a) the Optimum-Fixed Time Management (OFTM) and (b) Vehicle-Actuated Management (VAM4).

reduction rates for average vehicle delay decrease down to $15 \%$ and reduction rates for fuel consumption and exhaust emission decrease down to $10 \%$. These results show that the vehicle-actuated management systems are not efficient systems for specified traffic demand conditions;

- For not-fluctuated traffic demands, when the total traffic demand at the intersection is low, moderate, or high, average vehicle delay can be reduced in the range of about $5 \%$ and $20 \%$ and fuel consumption and exhaust emission can be reduced in the range of about $3 \%$ and $9 \%$;

- For the not-fluctuated traffic demands, when the total traffic demand at the intersection is very high, it can be seen that the reduction rates for average vehicle delay increase up to $30 \%$ and reduction rates for fuel consumption and exhaust emission increase up to $18 \%$. These results show that the vehicle- 


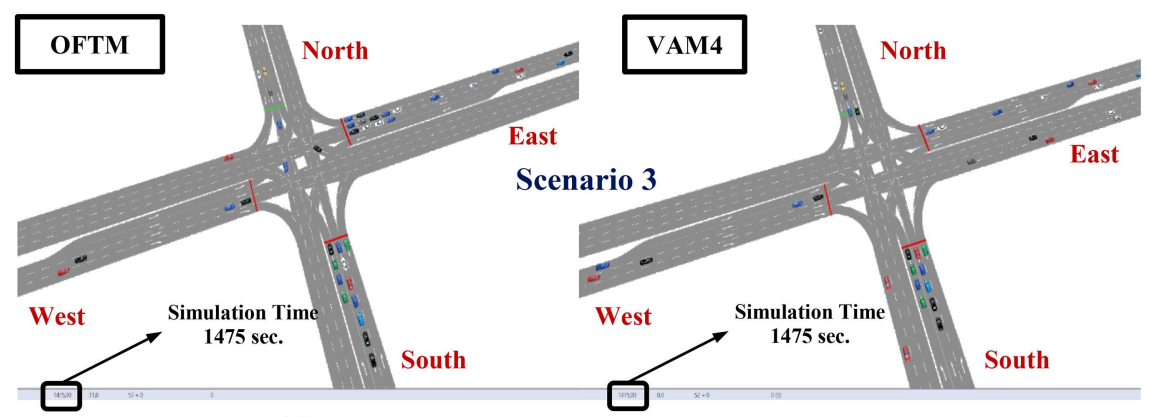

(a)

(b)

Figure 11. Scenario 3 when the fluctuations do not exist in traffic demands. Sample intersection view at the same time interval in case of implementing: (a) the Optimum Fixed-Time Management (OFTM) and (b) Vehicle-Actuated Management (VAM4).

Table 7. The obtained reduction rates (success rates) for the cases of fluctuating and not-fluctuating traffic demands.

\begin{tabular}{ccccccc}
\hline & \multicolumn{5}{c}{$\begin{array}{c}\text { For created scenarios, obtained reduction rates (\%) } \\
\text { in case of implementing }\end{array}$} \\
\cline { 2 - 6 } PAM4 instead of OFTM
\end{tabular}

actuated management systems are very effective systems for specified traffic demand conditions;

When the cases of whether the fluctuations in traffic demands exist or not are investigated separately, the obtained results are presented in Table 7 in detail. As seen in Table 7 , for the created scenarios the results are as follows:

- For not-fluctuated traffic demands, in case of implementing VAM4 instead of OFTM, the obtained reduction rates for average vehicle delay are about $4.5 \%$ minimum, $29.2 \%$ maximum, and $14.2 \%$ average. For the fuel consumption and exhaust emission, these rates are about $2.8 \%$ minimum, $17.7 \%$ maximum, and $7.3 \%$ average;

- For fluctuated traffic demands, in case of implementing VAM4 instead of OFTM, the obtained reduction rates for average vehicle delay are about $15.6 \%$ minimum, $58.6 \%$ maximum, and $32.5 \%$ average. For the fuel consumption and exhaust emission, these rates are about 9.6\% minimum, 38.4\% maximum, and $21.8 \%$ average.

According to the obtained results, the developed VAM4 is more effective in case of fluctuating traffic demands. For fluctuating traffic demands, reduction rates for all performance criteria increase about three times compared to not-fluctuated traffic demands in case of implementing VAM4 instead of OFTM.

\section{Discussion and conclusion}

In this study, a VAM4 that can adapt to fluctuations in traffic demands was developed. The effectiveness of the developed system was tested considering whether the fluctuations in traffic demands exist or not. Obtained results from this study can be summarized as follows:

- When the fluctuations in traffic demands did not exist, lower average vehicle delay, fuel consumption, and exhaust emission values were obtained with VAM4 compared to OFTM. When Figure 12 is examined carefully, especially in case of very high traffic demand at the intersection, reduction rates for all performance criteria increase. One of the main reasons for this situation is that the constraint of maximum green time of $45 \mathrm{sec}$ for OFTM is lower than that of maximum green time of $60 \mathrm{sec}$ for VAM4. The increase of maximum green time length for VAM4 led to the lower waste of time for vehicles in intersection approaches where the traffic demand was very high. Thus, average vehicle delays, fuel consumption, and exhaust emissions were significantly reduced;

- When the fluctuations in traffic demands existed, the effectiveness of OFTM decreased and average vehicle delay, fuel consumptions, and exhaust emissions significantly increased. Average vehicle delay, fuel consumption, and exhaust emissions were 

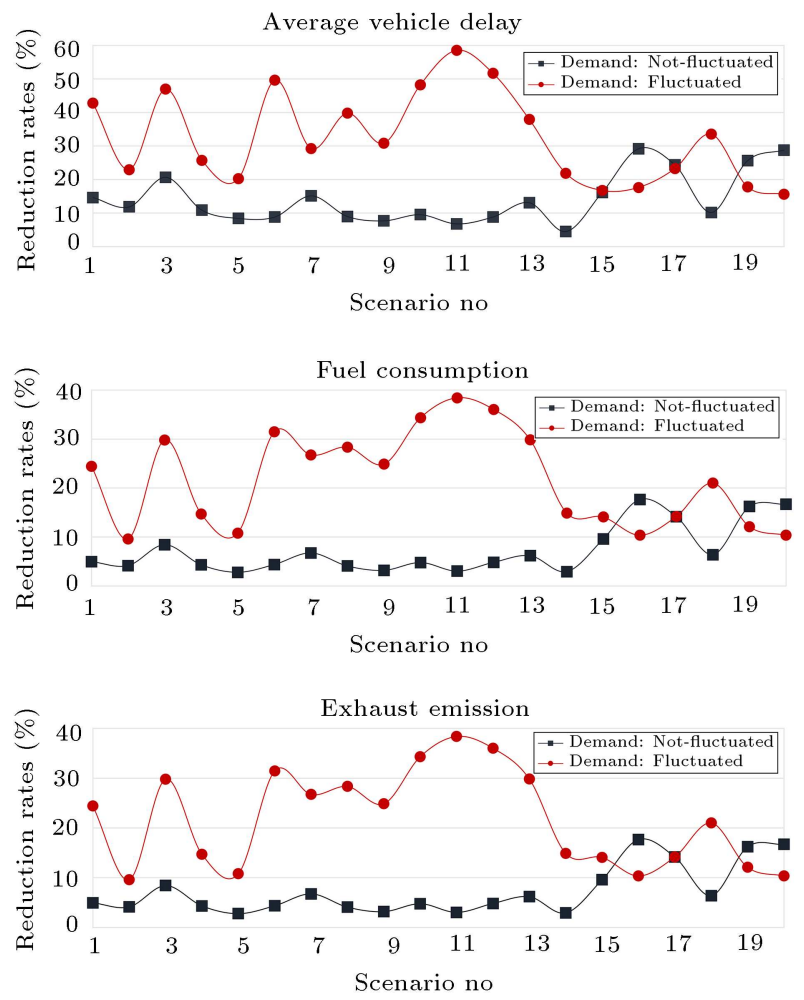

Figure 12. Obtained reduction rates in case of implementing the vehicle-actuated management instead of optimum fixed-time management for each performance criterion.

significantly reduced with the implementation of VAM4, especially in case of low, moderate, and high traffic demands at the intersection. In case traffic demand at the intersection was very high, reduction rates decreased. This situation arose due to the increase of the usage of maximum green time by different intersection approaches. It was determined that the density of the usage of maximum green time was an important factor that encouraged the increase of delay, fuel consumption, and exhaust emission;

- For the created scenarios, when the fluctuations in traffic demands did not exist, in case of VAM4 implementation instead of OFTM, the average vehicle delay was reduced by about $14.2 \%$, on average. Besides, fuel consumption and exhaust emissions were reduced by about $7.3 \%$, on average. When the fluctuations in traffic demand existed, these rates increased 2.5-3 times;

- When the fluctuations in traffic demands did not exist, in case of implementing VAM4 instead of OFTM, the service level for only five scenarios was enhanced. When the fluctuations in traffic demands existed, the service level in the fourteen scenarios was enhanced.
All obtained results demonstrate that VAM4 can effectively adapt to fluctuations in traffic demands. In addition to this, it is thought that the effectiveness and the performance of VAM4 can be improved more using different computational approaches.

\section{Acknowledgments}

The authors would like to thank PTV (Planung Transport Verkehr AG) for making VISSIM simulation software available to us.

\section{References}

1. Li, J-Q., Wu, G., and Zou, N. "Investigation of the impacts of signal timing on vehicle emissions at an isolated intersection", Transp. Res. D Transp. Environ., 16(2011), pp. 409-414 (2011).

2. Asadi, H., Tavakkoli Moghaddam, R., Shahsavari Pour, N., et al. "A new nondominated Sorting genetic algorithm based to the regression line for fuzzy traffic signal optimization problem", Sci. Iran., 25(3), pp. 1712-1723 (2018).

3. Yang, L., Zhang, L., Stettler, M.E.J., et al. "Supporting an integrated transportation infrastructure and public space design: A coupled simulation method for evaluating traffic pollution and microclimate", Sustain. Cities Soc., 52(2020), p. 101796 (2020).

4. Barzegar, S., Davoudpour, M., Meybodi, M.R., et al. "Formalized learning automata with adaptive fuzzy coloured petri net; An application specific to managing traffic signals", Sci. Iran., 18(3), pp. 554-565 (2011).

5. Samadi, S., Rad, A.P., Kazemi, F.M., et al. "Performance evaluation of intelligent adaptive traffic control systems: A case study", J. Transp. Technol., 2, pp. 248-259 (2012).

6. McKenny, D. and White, T. "Distributed and adaptive traffic signal control within a realistic traffic simulation", Eng. Appl. Artif. Intell., 26, pp. 574-583 (2012).

7. Vilarinho, C. and Tavares, J.P. "Real-time traffic signal settings at an isolated signal control intersection", Procedia Soc. Behav. Sci., 3, pp. 1021-1030 (2014).

8. Dabiri, S. and Abbas, M. "Arterial traffic signal optimization using particle swarm optimization in an integrated VISSIM-MATLAB simulation environment", 2016 IEEE 19th International Conference on Intelligent Transportation Systems, Rio de Janerio, Brazil, pp. 766-771 (2016).

9. Abdelghaffar, H.M., Yang, H., and Rakha, H.A. "Isolated traffic signal control using Nash bargaining optimization", Glob. J. Res. Eng. B., 16(1), pp. 1-11 (2016).

10. Li, Z., Shahidehpour, M., Bahramirad, S., et al. "Optimizing traffic signal settings in smart cities", IEEE T. Smart Grid, 8(5), pp. 2382-2393 (2017). 
11. Hashim, I., Ragab, M., and Asar, G. "Optimization of vehicle delay and exhaust emissions at signalized intersections", Adv. Transp. Stud. A., 46(2018), pp. $5-18$ (2018).

12. Yao, Z., Jiang, Y., Zhao, B., et al. "A dynamic optimization method for adaptive signal control in a connected vehicle environment", J. Intell. Transp. Syst., 24(2), pp. 184-200 (2019).

13. Grether, D., Bischoff, J., and Nagel, K. "Traffic actuated signal control: Simulation of the user benefits in a big event real-world scenario", 2nd International Conference on Models and Technologies for Intelligent Transportation Systems, pp. 1-4 (2011).

14. Bullen, A.G.R. "Effects of actuated signal settings and detector placement on vehicle delay", Transp. Res. Rec., 1244, pp. 32-38 (1989).

15. Mathew, T.V., "Signalized intersections delay models", Lecture Notes in Transportation System Engineering (2017).

16. Villiers, C., Nguyen, L.D., and Zalewski, J. "Evaluation of traffic management strategies for special events using probe data", TRIP, 2(2019), p. 100052 (2019).

17. Van Katwijk, R.T. "Multi-agent look-ahead trafficadaptive control", PhD Thesis, Technische Universiteit Delft, Delft (2008).

18. Gundogan, F. "Simplified traffic responsive signal control method for developing large cities", PhD Thesis, Graz University of Technology, Graz (2012).

19. Webster, F.V., Traffic Signal Settings Report (1958).

20. Mohajerpoor, R., Saberi, M., and Ramezani, M. "Analytical derivation of the optimal traffic signal timing: Minimizing delay variability and spillback probability for undersaturated intersections", Transp. Res. B Meth., 119 (2019), pp. 45-68 (2019).

21. Lian, F., Chen, B., Zhang, K., et al. "Adaptive traffic signal control algorithms based on probe vehicle data", J. Intell. Transp. Syst., 25(2021), pp. 41-57 (2021).

22. Akcelik, R. "Estimation of green times and cycle time for vehicle actuated signals", Transp. Res. Rec., 1457, pp. 63-72 (1994).

23. Mirchandani, P. and Head, L. "A real-time traffic signal control system: Architecture, algorithms and analysis", Transp. Res. C Emerg. Technol., 9(2001), pp. 415-432 (2001).

24. Angulo, E., Romero, F.P., Garcia, R., et al. "An adaptive approach to enhanced traffic signal optimization by using soft-computing techniques", Expert Syst. Appl., 38, pp. 2235-2247 (2011).

25. Yu, D., Tian, X., Xing, X., et al. "Signal timing optimization based on fuzzy compromise programming for isolated signalized intersection", Math. Probl. Eng., 2016, 1682394, pp. 1-12 (2016).
26. Hao, R., Wang, L., Ma, V., et al. "Estimating signal timing of actuated signal control using pattern recognition under connected vehicle environment", PrometZagreb, 33(1), pp. 153-163 (2021).

27. Li, H. and Prevedouros, P.D. "Traffic adaptive control for oversaturated isolated intersections: Model development and simulation testing", J. Transp. Eng., 130(5), pp. 594-601 (2004).

28. Viti, F. and van Zuylen, H.J. "A probabilistic model for traffic at actuated control signals", Transp. Res. C Emerg. Technol., 18(2010), pp. 299-310 (2010).

29. Trabia, M.B., Kaseko, M.S., and Ande, M. "A twostage fuzzy logic controller for traffic signals", Transp. Res. C Emerg. Technol., 7(1999), pp. 353-367 (1999).

30. Kim, J.T. and Courage, K.G. "Evaluation and design of maximum green time settings for traffic-actuated control", Transp. Res. Rec., 3606, pp. 246-255 (2003).

31. Guo, W., Yu, Z., He, Z., et al. "Traffic-actuated signal control based on dynamic optimal maximum green time", International Conference on Transportation Engineering 2007 (ICTE 2007), pp. 582-587 (2007).

32. Zheng, X., Recker, W., and Chu, L. "Optimization of control parameters for adaptive traffic-actuated signal control", J. Intell. Transp. Syst., 14(2), pp. 95-108 (2010).

33. Jiang, X., Qiu, Y., and Ruan, S. "An approach to optimize the settings of actuated signals", J. Mod. Transp., 19(1), pp. 68-74 (2011).

34. Swaminathan, N., Rathinawel, N., Duraisamy, S., et al. "Design of vehicle actuated signal using simulation", Gradevinar, 7(2014), pp. 635-641 (2014).

35. Guo, Y. and Ma, J. "An improved actuated signal control of intersection based on VISVAP", 6th International Conference on Sensor Network and Computer Engineering, pp. 123-128 (2016).

36. Ribeiro, I.M. and Simoes, M.L.O. "The fully actuated traffic control problem solved by global optimization and complementarity", Eng. Optim., 48(2), pp. 199212 (2016).

37. Lee, S.H. and Han, D. "Safety impacts of the actuated signal control at urban intersections", Promet-Zagreb, 28(1), pp. 31-39 (2016).

38. Wang, X.B, Yin, K., and Liu, H. "Vehicle actuated signal performance under general traffic at an isolated intersection", Transp. Res. C Emerg. Technol., 95(2018), pp. 582-598 (2018).

39. Promraksa, T., Satiennam, T., and Satiennam, W. "Vehicle actuated signal control for low carbon society", Int. J. GEOMATE, 16(55), pp. 86-91 (2019).

40. Highway Capacity Manual, National Research Council, Washington, D.C. (2010). 
41. Dogan, E. "Isolated signalized intersection control by optimized fuzzy logic method", PhD Thesis, Kirikkale University, Institute of Natural and Applied Sciences, Kirıkkale (2014).

42. Akcelik, R. "Traffic Signals: capacity and timing analysis", Australian Road Research Board, Research Report ARR No: 123 (1998).

43. Murat, Y.S. and Kikuchi, S. "The fuzzy optimization approach: A comparison with the classical optimization approach using the problem of timing a traffic signal", Transp. Res. Rec., 2024, pp. 82-91 (2007).

44. Ceylan, H. and Bell, M.G.H. "Traffic signal timing optimisation based on genetic algorithm approach including drivers' routing", Transp. Res. B Meth., 38(4), pp. 329-342 (2004).

45. Keskinturk, T. "Differential evolution algorithm", $J$ Ins. Nat. App. Sci. of Istanbul Ticaret University, 9(2006), pp. 85-99 (2007).

46. Baskan, O. and Ceylan, H. "Differential evolution algorithm based solution approaches for solving transportation network design problems", Pamukkale University J. Eng. Sci., 20(9), pp. 324-331 (2014).

47. Dogan, E. and Akgungor, A.P. "Optimizing a fuzzy logic traffic signal controller via the differential evolution algorithm under different traffic scenarios", Simulation, 92(11), pp. 1013-1023 (2016).

48. Korkmaz, E. and Akgungor, A.P. "Delay estimation models for signalized intersections using differential evolution algorithm", Int. J. Eng. Res., 5(3), pp. 16-29 (2017).

49. Baskan, O. and Ozan, C. "Determining optimum configuration of one-way and two-way streets using shortest path travel costs based on results of traffic assignment", Pamukkale University J. Eng. Sci., 24(6), pp. 1087-1092 (2018).

50. Yu, L., Yu, L., Chen, X., et al. "Calibration of VISSIM for bus rapid transit systems in Beijing using GPS data", J. Public Trans., 2006 BRT Special Edition, pp. 239-257 (2006).

\section{Biographies}

Ziya Cakici received BSc degree from Civil Engineering Department of Celal Bayar University, Manisa,
Turkey in 2010. He received the MSc and PhD degrees in transportation engineering from Graduate School of Natural and Applied Sciences at Pamukkale University (Turkey), in 2014 and 2020, respectively. He has been working as Assistant Professor in Department of Civil Engineering at İzmir Democracy University. His areas of interest lie in the fields of traffic management (especially Intelligent Transportation Systems), traffic and transportation planning and traffic optimization. He has published several papers in different journals and international conference proceedings.

Yetis Sazi Murat received BSc degree from Civil Engineering Department of Dokuz Eylul University, Izmir, Turkey in 1992. He has received MSc degree from Pamukkale University in 1996 and $\mathrm{PhD}$ degree from Istanbul Technical University in 2001. He has been working as a Professor at the Department of Civil Engineering at Pamukkale University. He worked as a visiting scholar at Virginia Tech. University, Falls Church, USA in 2006 (6 months) and University of Nevada, Reno, USA in 2017. He has published many technicalscientific research papers and conducted many projects on different subjects of transportation en gineering. His main research interests include fuzzy logic and neural network based traffic management approaches. His areas of interest lie in traffic management (especially Intelligent Transportation Systems), traffic and transportation planning, traffic accidents, etc.

Metin Mutlu Aydin received BSc degree from Civil Engineering Department of Dokuz Eylul University, Izmir, Turkey in 2010. He received the MSc degree from Dokuz Eylul University in 2012 and PhD degree from Akdeniz University, Antalya, Turkey in 2017. He has been working an Associate Professor at the Department of Civil Engineering at Ondokuz Mayıs University. His areas of interest lie in the fields of traffic and transportation engineering. His research interests include modelling of the lane discipline, optimization of the intersection geometry, simulation of driver behaviours in general. He has published many research papers in different journals and international conference proceedings. 